Revista Iberoamericana, Vol. LXXV, Núm. 228, Julio-Septiembre 2009, 757-772

\title{
SUJETOS INSOLVENTES: JOSÉ ASUNCIÓN SILVA Y LA ECONOMÍA TRANSATLÁNTICA DEL LUJO
}

\author{
POR \\ ERICKA BECKMAN ${ }^{1}$ \\ University of Illinois, Urbana-Champaign
}

En julio de 1890, el poeta y novelista colombiano José Asunción Silva se disculpó en una carta con su amigo el antioqueño Eduardo Zuleta por no escribir sobre cuestiones artísticas, explicando que una incesante cadena de infortunios financieros habían obstruido las imágenes de belleza que hubiera deseado expresar. Lamentándose por su transformación en un “Abragleforlífero”, discordante referencia a la darwiniana lucha por la existencia, Silva señala que en vez de escribir poesía, ha de preocuparse por el "cambio de Libras Esterlinas por papel moneda y de uno o dos centavos en el precio del café en las últimas cuentas del Havre” (Cartas 71). Para Silva, la posibilidad del arte queda truncada por las condiciones económicas de un capitalismo periférico, marcado por las fluctuaciones de un único cultivo de exportación y por la caída del papel moneda.

La razón por la cual Silva se preocupaba por las tasas de cambio era que, además de ser escritor, también importaba artículos de lujo para comerciar en la Bogotá de los noventa. Su participación en esta empresa coincidió con un gran boom cafetero en Colombia, ya que las exportaciones eran acompañadas por un paralelo auge importador de artículos de lujo (en su mayor parte, europeos) destinados al consumo de la pequeña elite criolla del país. Pero, tal y como atestigua la carta de Silva, incluso los booms estaban sujetos a la volatilidad. Dadas las inestables y a menudo desfavorables condiciones bajo las cuales Silva debía operar, no es sorprendente que él mismo viera la economía como un obstáculo para la contemplación artística. Y efectivamente, Silva era notoriamente desafortunado en sus negocios: la inestabilidad de la economía cafetera, así como la crisis económica global y sus propios hábitos de gasto excesivo, desembocaron en una escandalosa bancarrota en 1894. En esa misma época, Silva afrontó dos golpes adicionales: la muerte de su hermana Elvira y la pérdida de sus manuscritos literarios en un

\footnotetext{
1 Agradezco la ayuda editorial de Diana Arbaiza.
} 
naufragio al regreso de una breve estadía en Caracas como funcionario consular. Arruinado y deprimido, se suicidó en la casa familiar de Bogotá en 1896, apenas cumplidos los treinta y un años de edad.

Este ensayo busca situar a Silva dentro de las redes comerciales transatlánticas finiseculares, demostrando cómo su postura artística se articula a través de una serie de intercambios, transacciones y fracasos materiales. En particular, me enfoco en las múltiples significaciones que éste dio a los objetos de lujo que ocupaban el centro de sus avisos publicitarios y sus escritos literarios. Por lo general, Silva ha sido tratado como víctima de la sociedad comercial que lo rodeaba; mi análisis, en cambio, propone una relación más ambigua entre cuestiones estéticas y económicas. ${ }^{2}$ Por otra parte, mientras el consumo de bienes importados por parte de la elite criolla (sean estos muebles o doctrinas políticas francesas o inglesas) se ha visto como señal de la tendencia imitativa y poco auténtica de esta clase, en este ensayo muestro que los objetos de lujo europeos se insertaron de forma más compleja dentro de los proyectos de modernidad latinoamericanos.

A lo largo del siglo xix, los países de la región se incorporaron al intercambio global como proveedores de materias primas (tales como el café, el azúcar y el guano) y como consumidores de bienes "elaborados" de Europa y los Estados Unidos. Ya hacia fines del siglo, el comercio transatlántico aumentó a tal punto en un período de tiempo tan breve, que los historiadores han observado que, "quizás más que cualquier otra región del mundo, Latinoamérica fue una creación de la economía global” (Topik y Wells 5). ${ }^{3}$

Desde la dialéctica finisecular de la importación/exportación, este ensayo indaga sobre los imaginarios que surgieron bajo nuevos regímenes de comercialización en América Latina. Anivel simbólico, se puede trazar a través de los objetos importados un triángulo de intercambio que conectaba a Estados Unidos, Europa y Colombia. El café, que salía para los mercados de Estados Unidos, se convertía en suntuosos objetos de lujo comprados en Europa, efectuando una especie de transubstanciación de la mercancía. Al cruzar los mares, el café se convertía en dinero, para luego pasar a ser vestidos Worth, porcelanas Sèvres y cuadros de Watteau. Pero muchas veces, como quiero mostrar en mi lectura de Silva, el dinero y los objetos de lujo

2 La imagen de Silva como víctima de la sociedad comercial se ha convertido en un lugar común de la historiografía literaria colombiana. Véase, entre otros, los artículos reunidos en el volumen de Cobo Borda.

3 En palabras de los autores: "(a)rguably more than any other part of the globe, Latin America was a creation of the world economy” (Topik y Wells 5). Los años entre 1870 y 1914, han sido destacados como el auge de la era de la economía exportadora en América Latina. Tulio Halperín Donghi se refiere al período entre 1880 y 1930 como "la madurez del orden neocolonial” (cap. 5). Todas las traducciones son mías. 
se esfumaban ante la deuda y la bancarrota personales y nacionales, cerrando abruptamente los circuitos de intercambio transatlántico.

ARTE MODERNISTA, LUJO Y PUBLICIDAD

El suicidio de Silva ha sido interpretado como un desenlace particularmente trágico enmarcado en la lucha entre el arte y los negocios de las letras latinoamericanas. Según Camilo Brigard Silva, sobrino del escritor, la "extraordinaria sensibilidad del artista no era la más apropiada para el manejo de estos bajos intereses materiales” (284). Para el venezolano Rufino Blanco Fombona, Silva fue la víctima de un entorno tropical de "groseros comerciantes, sudados y prácticos” y "mujeres con el alma en el clítoris”. Estos sujetos, “¿cómo iban a comprender esa alma de selección, ese corazón atormentado, ese espíritu en angustia?” (69). Cabe destacar el hecho de que Blanco Fombona sugiere que Silva no habría corrido el mismo final en Francia o Alemania, donde hubiera sido admirado y valorado como artista.

Más recientemente, críticos como Ángel Rama han sostenido que Silva era incapaz de producir más arte porque en América Latina, en contraste con Europa, la literatura aún no se había profesionalizado lo suficiente a finales del siglo XIX, obligando al colombiano a mantenerse con otras actividades (64). Según esta lectura, la entrada del escritor al espacio mercantil como comerciante dio como resultado una obra literaria truncada e incompleta, interpretación que cuadra con las mismas quejas de Silva. Sin embargo, si consideramos la economía de la periferia, sacudida por frecuentes crisis y fracasos, no sólo como un espacio de negatividad sino también de productividad discursiva, podemos analizar un conjunto diferente de relaciones entre el artista de fin de siglo y las condiciones materiales en las que estaba inmerso.

Que Silva tuviera algo importante que decir, a propósito de las condiciones específicas de los proyectos de modernización latinoamericanos, puede sonar en principio poco intuitivo, ya que se ha considerado al autor, junto a sus colegas modernistas, como partidario de un discurso extremadamente esteticista que se alejaba conscientemente de la esfera política. Al mismo tiempo, miembros de esta tendencia respaldaron con entusiasmo una estética enraizada en artículos materiales, la mayor parte de los cuales eran artículos de lujo procedentes de Europa. Para los primeros críticos del modernismo, estas imágenes de lujo se convirtieron en una metáfora de la contemplación estética, “alejada de las impurezas de la vida diaria” (Henríquez Ureña 170).

Esta sensibilidad marca un cambio fuerte con respecto a la tradición cívica implantada por generaciones anteriores de letrados, que va desde Andrés Bello y D. F. Sarmiento hasta Eugenio María de Hostos y José Martí, quienes criticaban fuertemente al lujo como moralmente corrosivo y feminizante e insistían en la 
utilidad social de la escritura. ${ }^{4}$ En particular Martí, muchas veces nombrado entre los poetas modernistas por sus renovaciones formales, se distingue entre esta cofradía precisamente por su fuerte rechazo al lujo. Silva, en cambio, junto con figuras como Rubén Darío y Julián del Casal, celebraría los placeres del exceso material que permitían la expansión comercial, a la vez que se posicionaba encima de los intereses burgueses. ${ }^{5}$ Para estas últimas figuras, el desinterés artístico -precepto básico del modernismo finisecular- se metaforizaba en el lujo. Bajo este punto de vista, el lujo y el arte se unían en su absoluta falta de finalidad.

Estudiar a Silva desde las relaciones comerciales transatlánticas nos permite encontrar otro lugar desde donde entender el consumo de objetos extranjeros, no como imitación, sino como lugar de creación de relaciones sociales y discursivas. Para indagar sobre las inflexiones particulares de la estética de Silva, vayamos al primer párrafo de su novela póstuma, De sobremesa, en el cual presenciamos un ejemplo de la estética enraizada en los objetos de lujo importados. En este texto, un narrador omnisciente describe el suntuosamente decorado salón del protagonista José Fernández, un criollo diletante que recientemente ha regresado de Europa a su casa en Sudamérica:

Recogida por la pantalla de gasa y encajes, la claridad tibia de la lámpara caía en círculo sobre el terciopelo carmesí de la carpeta, y al iluminar de lleno tres tazas de China, doradas en el fondo por un resto de café espeso, y un frasco de cristal tallado, lleno de licor transparente entre el cual brillaban partículas de oro, dejaba ahogado en una penumbra de sombría púrpura, producida por el tono de la alfombra, los tapices y las colgaduras, el resto de la estancia silenciosa. (109)

Nos encontramos aquí con una exaltada descripción de un espacio interior, la cual se puede leer como una versión latinoamericana de una estética de la enumeración que ya había sido ensayada por autores franceses como Balzac, J. K. Huysmans y los hermanos Goncourt. También tenemos una versión de la "domesticidad del macho" descrito por Janell Watson, a través del cual el esteta soltero transforma el interior burgués en obra de arte (76). Sin embargo, la estética empleada por Silva no es una mera copia; ya el contexto desde el cual habla es muy diferente al de sus

4 Muchos historiadores han mostrado cómo la revolución comercial en Gran Bretaña durante el siglo XVIII provocó nuevos debates sobre el lujo, desde luego signo de la corrupción moral dentro de las tradiciones políticas y religiosas de Occidente. Junto con la especulación financiera y el crédito, el lujo -invariablemente representado como fuerza femenina y extranjera- llegó a encarnar ansiedades acerca de la inestabilidad y la duplicidad inherentes a la nueva sociedad comercial (véase Pocock, Sekora). Mi análisis no pretende ser exhaustivo sino que propone trazar algunos de los mismos miedos que representaba el lujo en América Latina a fines del siglo XIX.

5 El cuento "El rey burgués" es el ejemplo mejor conocido de la estética lujosa de Darío, la cual se contrapone al utilitarismo e interés del mundo comercial. Muchos de los poemas de Casal, por otra parte, elaboran un nexo entre lujo, arte y exotismo oriental. 
cofrades metropolitanos. En un escenario latinoamericano, para empezar, los objetos que adornan el salón necesariamente tendrían que haber sido importados desde Europa o el Lejano Oriente (a través de comerciantes europeos). Y mientras el lujo siempre ha traído connotaciones de exotismo, sobre todo a través de convenciones orientalistas, en este contexto el lujo trae una fantasía del gusto y refinamiento europeos, componente clave de la actuación del esteta periférico.

Demanera significativa, el único objeto en el ficticio catálogo de objetos de Silva que podría haber sido producido localmente es el café (un estimulante que comenzó su trayectoria comercial siendo un artículo de lujo para los europeos) servido en delicadas tazas de té chinas. Asumiendo que la novela se desarrolla en el Bogotá de los noventa, es muy probable que artículos como los descritos anteriormente hubiesen sido pagados con exportaciones de café. Como el mismo Silva sabía muy bien, el precio de esta mercancía en los mercados internacionales determinaba el poder adquisitivo de la elite bogotana, la cual iba en ascenso en los años noventa. En este período, un creciente número de bienes de consumo europeos fueron transportados a Bogotá a través de una ruta ardua y extremadamente complicada. Ya que ninguna línea ferroviaria ni ningún río conectaban la capital con las costas, todos los objetos - pianos incluidos- tenían que ser transportados por mulas o a “lomo de indio” desde las tierras bajas del Río Magdalena hasta Bogotá, a través de las cadenas montañosas de los Andes.

El párrafo inicial de De sobremesa omite cualquier referencia a las específicas dimensiones materiales de la economía de importación-exportación. En su lugar, Silva nos ofrece un salón silencioso, lleno de objetos misteriosos. Dada la atmósfera claustral de este espacio interior europeizado, se comprende fácilmente cómo podríamos desestimar la sensibilidad de Silva, considerándolo desesperadamente apolítico, escapista y, en última instancia, poco auténtico. Aunque ciertamente eurocéntrico y elitista, el mundo fantástico de Silva mantiene una relación con sus condiciones locales de enunciación, más cercana de lo que parece en primera instancia. En 1890, seis años antes de que reescribiese De sobremesa, Silva había ensayado el mismo estilo literario en las páginas del diario bogotano El Telegrama:

La cortina de felpa bordada de oro caía sobre un transparente que filtraba la luz amortiguándola con el tono oscuro del brocatel de los muebles, con la madera opaca del piano y con el brillo de los marcos de las pinturas. Había en el aire del cuarto una fragancia de agua de toilette que completaba el ambiente lujoso de la pieza. Sobre el tocador un espejo triple reflejaba los grandes frascos de agua de colonia [...]. (citado en Santos Molano 972) ${ }^{6}$

\footnotetext{
6 Para detalles acerca de la vida comercial de Silva, incluyendo los avisos publicitarios que escribió para su negocio, me he apoyado en la inmensa y valiosísima biografía de Enrique Santos Molano, El corazón del poeta.
} 
Las similitudes entre este texto y el párrafo inicial de De sobremesa son llamativas: en ambos se describe un interior lujoso en el que la luz, filtrada a través de diáfanas telas y absorbida por oscuros tejidos, ilumina objetos específicos aislados por la mirada del narrador: marcos de cuadros, la madera del piano y decantadores de cristal. No es simplemente el tipo de objetos exhibidos lo que hace a estos pasajes similares, sino el lenguaje utilizado para describirlos. En ambos, un desfile de adjetivos pretende capturar el detalle del lujo.Asimismo, el uso del tiempo imperfecto permite que se acumulen los objetos, creando un paisaje inorgánico poblado de bienes exquisitos. Pero el segundo texto citado, a diferencia del primero, no fue escrito como parte de una novela, sino como un aviso publicitario para El Almacén Nuevo, la recién inaugurada tienda de Silva, la que el escritor imaginaba como la respuesta local a las grandes tiendas parisinas como Au Bon Marché.

Mientras que el anuncio fue publicado en 1890, la novela fue reescrita entre 1894 y 1896 (tras perderse una versión anterior en un naufragio), y publicada en 1925. ¿Qué significa que la estética empleada dentro de la novela de Silva había funcionado años antes como propaganda comercial de decoración del hogar? Esta confluencia es importante, porque el lenguaje descriptivo que identificamos con el proyecto estético de Silva aquí se utiliza para fines abiertamente comerciales, mostrando cómo una posición de “desinterés” artístico, en ocasiones, era totalmente compatible con los intereses comerciales.

La razón por la cual estos dos textos pueden funcionar en un registro similar es porque ambos contienen objetos que se codifican como bellos, revelando un sustrato comercial en la producción artística de Silva y un componente estético en los discursos de marketing de fin de siglo. El literario anuncio de Silva nos demuestra cómo el mismo acto de anunciar implica una propuesta estética, ya que es de interés incitar un deseo que derive en la compra. De esta forma, el anuncio de Silva es digno de mención, no sólo porque se asemeja al discurso literario, sino porque destaca las funciones paralelas de la literatura y el anuncio como géneros de seducción y fantasía. Pero si bien es cierto que tanto la literatura como la publicidad son formas de escribir altamente mercantilizadas en la modernidad capitalista, lo son de diferentes maneras. Porque si la literatura puede a veces considerarse un fin en sí mismo, esto nunca ocurre con la publicidad, un género que existe como pretexto para el consumo de los bienes representados. Es precisamente gracias a esta diferencia que Silva, en el ejemplo citado arriba, puede apelar simultáneamente a registros del desinterés estético y al consumo de mercancías.

Por otra parte, la confluencia entre aviso y novela demuestra que no fue solamente la estética literaria de Silva algo basado en la fantasía, sino también el mismo acto de consumir, aspecto que podemos apreciar desde el paradigma reinante de la sociedad comercial actual. Porque más que destacar las calidades de cualquier 
objeto singular, el anuncio produce un ambiente de belleza, prestigio y exclusividad, el cual "vale" más que la suma de sus componentes materiales.

Aprimera vista, ambas descripciones de Silva sitúan el valor estético por encima del valor de cambio de los artículos, posibilidad condicionada por la calidad de los objetos en cuestión. Sin embargo, para que el anuncio sea efectivo, debe finalmente decir a los lectores que estos magníficos objetos están a la venta. Realizando un radical cambio de tono, el anuncio añade: "Todo había sido comprado, a precios muy razonables en el Almacén Nuevo [...] sin duda el mejor almacén de muebles y artículos de fantasía de Bogotá” (Santos Molano 972). Silva, el artista, proporciona una fantasía sólo para que Silva el anunciante informe a los clientes sobre el lugar donde pueden venir a comprarla.

La fusión de forma estética einterés comercial no para aquí. Entreel considerable corpus de anuncios de Silva se encuentran cartas intercambiadas entre dos clientas, Inés y Beatriz, quienes se turnan para describir las "preciosidades" de la tienda del señor Silva, hombre que aparece como personaje de su propia ficción comercial (Santos Molano 975). También inventa reportajes sobre matrimonios, en los cuales todos los regalos habían sido comprados en el Almacén Nuevo (Santos Molano 972). En otro caso, Silva escribe versos alejandrinos a cargo de un competidor, el Almacén Bohemia:

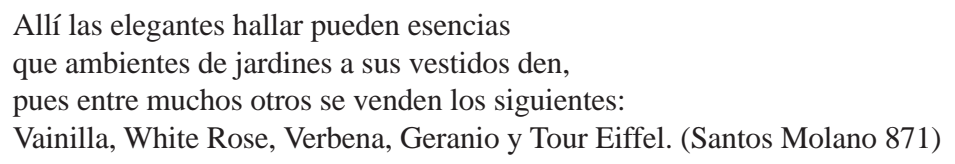

Aquí Silva emplea la versificación de catorce sílabas divididas en dos hemistiquios de siete sílabas cada uno, igualmente trabajado por poetas como Rubén Darío en la misma época. ${ }^{7}$ Pero la renovación lingüística tan estudiada del modernismo se lleva a cabo a través de la rítmica adaptación de nombres de mercancías extranjeras destinadas para la venta a consumidoras. En este y otros casos, un lenguaje feminizado del consumo se fusiona con la forma poética en lo que podríamos identificar como la escondida prehistoria comercial del discurso literario finisecular.

\section{LUJO Y CONSUMO “CIVILIZADO”}

Las connotaciones femeninas del lujo europeo coexistieron de forma incómoda con el refinamiento europeo que prometía esta misma actividad. Quizás no deba sorprender este intento por "poetizar" a ciertas mercancías, ya que el consumo de

7 Véase, por ejemplo, el poema de Darío “Era un aire suave”. 
importaciones (especialmente las francesas) funcionaba como signo de la pertenencia metropolitana, en ausencia de otros signos materiales de "progreso". El predominio de la producción de materias primas, la ausencia de industrialización y la falta de un cuerpo social "blanco" formaban una conocida letanía de quejas que manifestaban las elites criollas de fin de siglo. De manera significativa, la producción de materias primas estaba conectada con los discursos raciales de la época, ya que las naciones dedicadas al cultivo de caféy a la extracción de minerales eran consideradas inferiores a las naciones manufactureras, un mito colonial sostenido por los seguidores deAdam Smith y Karl Marx. O, como el peruano Luis Esteves señaló en 1882, los países productores de materias primas eran por naturaleza "bárbaros", mientras que los países que transformaban estas materias primas en manufacturas eran "civilizados", dando una inflexión económica a la clásica dicotomía sarmientina (35).

Durante la época de Silva, el consumo de artículos europeos llegó a ser una solución parcial para este dilema, táctica que se revela en una de sus "crónicas bogotanas”, en la cual asume la voz de una mujer norteamericana, Mary Bell, para expresar su consternación ante la baja calidad de los artículos producidos en Colombia:

No halló una sola producción nacional que diera indicios de vigor, de vida abundante, de actividad humana aplicada a trabajos serios. Mucha cosa menuda de paja, de madera o de chocolate, juegos minúsculos del ingenio manual; prendas inútiles; bordado, dibujos con tinta y con lápiz [...] Ni rastros siquiera de una empresa grandiosa, de una industria de esas que hacen el nombre y la riqueza de un país. (Santos Molano 983)

Aquí encontramos lo contrario a los catálogos de artículos importados antes examinados. En vez de fluidas descripciones de artículos europeos y de Asia, tenemos frases cortas y puntuales que imitan lingüísticamente la supuesta inferioridad de los productos locales, los cuales tendrían que ser reemplazados por importaciones norteamericanas o europeas. Este anti-anuncio para la producción nacional se publicó en 1891, el mismo año del discurso más famoso de José Martí, "Nuestra América", en el que el escritor cubano excoria a las elites por consumir importaciones extranjeras a costa del desarrollo americano. Silva, por otro lado, exhorta a lo opuesto: incluso permite que una mujer norteamericana induzca a los lectores a sentirse avergonzados de la producción nacional, y a consumir, por el contrario, los frutos de lugares más "civilizados".

Vale la pena destacar brevemente aquí que para Silva, el triángulo Estados Unidos-Europa-Colombia necesariamente obviaba la presencia de España, viejo poder colonial y persistente referente cultural en Bogotá, ciudad que (a diferencia de ciudades como Buenos Aires) se aferraba a su identidad hispana, católica y criolla. 
Los objetos de lujo que ofrecía Silva pertenecían al nuevo orden económico y a la vez cultural centrado en Estados Unidos y el norte de Europa. Los conservadores entonces en el poder se mantenían fuertemente en contra del lujo como un pecado que iba contra la humildad cristiana y las jerarquías sociales naturales; en línea con este conservadurismo social, el gobierno liderado por Rafael Núñez y luego por Miguel Antonio Caro instituyó medidas económicas proteccionistas y un régimen de papel-moneda nacional como intento de controlar los cada vez más crecientes flujos de dinero y mercancías que entraban a Colombia. Pero no fueron solamente los conservadores católicos y proteccionistas quienes se oponían al consumo de importaciones de lujo. El principal exponente del liberalismo de aquella época, Miguel Samper, quería liberalizar el comercio, pero a la vez contener los deseos estimulados por la expansión económica. Una figura legendaria por su austeridad, Samper se alarmaba cada vez más ante el desequilibrio entre producción nacional y el consumo de objetos extranjeros, señalando que en el libro de vida nacional, “el Haber del bien sigue en blanco”, mientras en el débito “encontramos la codicia, el lujo, la disipación, la bebida y el juego” (142). Silva buscaba incitar los mismos deseos que Samper quiso contener, colocando al poeta-comerciante en una posición más radicalmente liberal que la del famoso economista político.

Silva, entonces, era partidario no sólo de la literatura decadente francesa dentro de un medio social conservador e hispanista, como se suele destacar. También fue partidario del intercambio sin barreras entre Colombia y el resto del mundo, promocionó objetos extranjeros por sobre sus versiones locales y buscó liberar los deseos en la esfera del consumo. De esta forma, la propuesta estética de Silva se reforzaba por la ideología librecambista que competía con las posturas hegemónicas de aquel entonces en la creación de nuevos patrones económicos y culturales.

LUJO Y BANCARROTA: DE SOBREMESA

En su corpus de anuncios, Silva incita a los consumidores a "comprar europeo”; y no sólo eso, también a entregarse a las fantasías del lujo, libres de antiguas restricciones morales y económicas. Este entusiasmo desmentía el hecho de que el lujo importado continuaba siendo una espada de doble filo, incluso para Silva, quien construyó su vida artística y comercial a base de estos objetos. Por una parte, suponía afirmar un ideal de modernidad europea mientras, necesariamente, se aceptaba que la periferia (y sus productos) eran inferiores por comparación. Al mismo tiempo, implicaba negociar con una contradictoria identidad de género que fácilmente confundía la pose del esteta masculino con la actividad de las nuevas consumidoras femeninas. Con respecto a esta ambigüedad, es importante recordar que Silva era conocido entre los miembros de su medio social como “José 
Presunción” o "La casta Susana”, apodos que conectaban la exquisitez del dandy con una dudosa sexualidad (Vallejo 72). ${ }^{8}$

Además, como advertían políticos liberales y conservadores, el creciente consumo de importaciones también amenazaba con crear un peligroso desequilibrio económico. Ya para el año 1890, se atisbaban señales de una crisis económica a nivel mundial, la cual sacudiría a las frágiles economías de exportación latinoamericanas con una serie de "cracks" en las bolsas de valores, devaluaciones monetarias y deudas impagables a la banca extranjera. Fue en este ambiente que Silva, al parecer inmune a las señales del desastre, siguió pidiendo préstamos y gastando en artículos de consumo personal. Según el análisis que hace Fernando Vallejo de los libros de contabilidad de Silva, éste siguió pidiendo ropa, cigarrillos egipcios, té cantonés hasta que su crédito simplemente se agotó. Al encontrarse en la ruina, Silva no encontró más remedio que publicar avisos, esta vez pidiendo más tiempo para pagar a sus acreedores locales (Vallejo 91-95). Con esto, las promesas de belleza, opulencia y civilización que había ofrecido el marchand de luxe se pusieron en irreversible liquidación, cortando los circuitos del intercambio transatlántico.

Lo que vivió Silva en sus últimos años también está ficcionalizado en su gran novela. De sobremesa, reescrita durante sus últimos días, es, a mi juicio, una reflexión estética sobre el desequilibrio económico que padeció el autor. Utilizando tácticas de la ironía y la parodia no disponibles en sus propagandas comerciales, la novela de Silva ofrece un diagnóstico del sujeto masculino insolvente, quien en vez de producir para la nación -como lo quisieron figuras cívicas como José Martí- sólo consume. En la novela, el personaje principal, José Fernández, lee su diario europeo en voz alta a los concurrentes de la sobremesa que abre la novela, en el que cuenta sus proezas en París, Londres y Suiza (los mismos lugares que visitó Silva en su primer y único viaje a Europa en 1885).

A pesar de ser inmensamente rico, José Fernández se destaca en la novela como un sujeto sumamente desequilibrado por no saber distribuir sanamente sus deseos, fuerzas y bienes. El consumo de lujo se perfila prominentemente como una de las fuentes de la enfermedad de José Fernández en De sobremesa, actividad que, como hemos visto, se liga no sólo a cuestiones de arte, sino también a las del comercio transatlántico. Como ya vimos, la novela abre con una descripción lujosa del salón americano de José Fernández, la cual fija el registro estético de la obra. Es en este espacio, tras una comida recién ingerida, donde los invitados de José Fernández musitan sobre la extraña enfermedad que éste ha adquirido durante su prolongada estadía en Europa. De forma apropiada, es un médico local quien hace el primer

\footnotetext{
8 Sobre la incomodidad crítica que ha provocado la ambigüedad sexual de Silva, véanse los excelentes
} estudios de Molloy y Montero. 
diagnóstico del mal del personaje, diciendo que tiene todo que ver con "el lujo enervante y el confort refinado de esta casa”, caracterizados por

esas joyas en cuya contemplación te pasas las horas fascinado por su brillo, como se fascinaría una histérica; el té despachado directamente de Cantón; el café escogido grano por grano que te manda Rovira; el tabaco de Oriente y los cigarros de Vuelta Abajo; el kummel ruso y el krishabarr sueco. (De sobremesa 116)

Claramente haciendo una parodia de los discursos de anti-lujo en el Bogotá de fin de siglo (articulados tanto por conservadores como por liberales), el médico destaca la enervación y feminización que conlleva el consumo de las importaciones de lujo. De forma cómica, sugiere que José Fernández vaya a vivir al campo, donde, entre gente simple y los libros prestados por un cura, podría enmendar sus malos hábitos y volver a escribir poesía.

Pero como cuenta el personaje, en cuanto más consume, más exigen sus sentidos, tendencia que lo lleva a buscar experiencias cada vez más refinadas. No es difícil aquí detectar un parentesco entre él y Des Esseintes de la novela A rebours (1884) de J. K. Huysman, personaje que sirvió de inspiración directa para Silva. Tanto José Fernández como Des Esseintes transforman la vida en obra de arte a través del consumo de libros raros, joyas y objets d'art; rechazan la noción burguesa del justo medio para entregarse al exceso sin límites; y aceptan, con gestos entre solemnes e irónicos, su denominación como seres “enfermos”. Y en ambos casos, la enfermedad se liga directamente con la pérdida de la virilidad a través del consumo de lujo: los lectores de A rebours recordarán una escena particularmente cómica en la que Des Esseintes hace un funeral para su virilidad tras dedicarse a la contemplación de objetos bellos; los amigos de José Fernández, por su parte, ven en su contemplación de las joyas señales de histeria. Al mismo tiempo, esta identificación ambigua con lo femenino se marca por elementos fuertes de misoginia, ya que ambos personajes continuamente afirman su odio hacia las mujeres.

Pero mientras Des Esseintes se enclaustra en su casa, aceptando su mal irremediable, José Fernández constantemente trata de rectificar su desequilibrio físico, psíquico y sexual. Quiero referirme a una instancia particularmente dramática del intento del personaje por sobreponer una afición por el consumo con una ética producción económica, la cual se puede leer como fábula cultural, no sólo sobre el consumo excesivo de bienes importados, sino también sobre la inestabilidad económica de los países productores de materias primas.

En una instancia particular del diario de José Fernández, el esteta periférico trata de enderezar inclinaciones hacia el lujo, para luego convertirse en sujeto masculino "productivo". El diario cuenta que, estando en París, descubrió a su amante francesa en la cama con otra mujer. Para vengar este ataque a su integridad 
masculina, trata de matarla. Sin embargo, en vez de blandir un arma de verdad para recuperar su honor, saca de su solapa una pequeña daga toledana adornada de joyas. La progresión esperada de la escena se corta de forma cómica, ya que el lujo ha anulado la posibilidad de reestablecer el poder fálico. Temiendo las repercusiones del intento de homicidio, José Fernández huye a Suiza, donde jura solemnemente: “¡Adiós, sensualidades de bizantino, a vivir vida de hombre!” (149).

Es aquí, en Suiza, la tierra del republicanismo rousseauniano y del protestantismo ascético, donde José Fernández trata de recuperar su virilidad soñando un plan grandioso de modernizar su país, un episodio contado en la entrada del diario para el 10 de julio (no por casualidad, quizás, el mes del comienzo de las batallas por la Independencia en Colombia en 1810). Asumiendo la pose de Bolívar delirando el futuro de la Gran Colombia sobre el Chimborazo, quien a su vez citó al naturalista alemán Alexander Von Humboldt (Pratt 181), José Fernández idea un grandioso plan para modernizar su país. En primer lugar, necesitaría adquirir capital mediante la venta de sus minas de oro sudamericanas a banqueros londinenses, ventas cuyas ganancias invertiría en los mercados estadounidenses. Mientras su capital se desarrollase por sí solo, reproduciéndose mágicamente con la ayuda de la familia Astor, él viajaría a través de los Estados Unidos “a estudiar el lenguaje de la civilización norteamericana” (141).

En el plan ficticio de José Fernández, el triángulo de intercambio material entre América Latina, Estados Unidos y Europa se perfila como una solución no sólo para la locura del protagonista, sino también para rectificar el atraso de la nación. Después de hacer sus inversiones en el exterior, viajaría a través de su propio país, catalogando minerales y cultivos para la exportación a Europa. Después de años de incesante estudio, habría desarrollado "un plan de finanzas racional, que es la base de todo gobierno" (142). Así, llegaría el día en el que la deuda del país se convertiría en un superávit, con el que se invertiría en ferrocarriles y puentes para promocionar aún más el comercio. Ayudado por consultas a famosos economistas europeos, el país se enriquecería, se industrializaría y atraería a oleadas de inmigrantes. El plan toma un vuelco distópico cuando José Fernández señala que los inmigrantes serían chinos (burlando el proyecto vigente del blanqueamiento a través de la inmigración), y que las fábricas ennegrecerían el aire nacional; a la vez, la guerra civil desataría una violencia que sólo podría ser controlada a través de una dictadura brutal.

Este plan, que aparece como un golpe genial de José Fernández, sonará sospechoso a los familiarizados con la historia latinoamericana del siglo xix, ya que es una amalgama de las medidas tomadas por los gobiernos a lo largo de este siglo para crear naciones-estados modernos, "civilizados” y fiscalmente solventes. En la mayoría de los casos, este plan no había dado como resultado riquezas fabulosas ni modernidad al estilo europeo; en cambio, había traído inestabilidad económica y una astronómica deuda en divisa fuerte. 
El delirio de José Fernández busca en las materias primas el motor de la modernización latinoamericana, que en De sobremesa se utilizan para comprar objetos de lujo. La novela cambia de planos temporales después del episodio suizo, trasladando la narración al "presente” en América. José Fernández interrumpe la lectura del diario, dirigiéndose a sus invitados: "Yo estaba loco cuando escribí esto, ¿no?” (148). Mientras el autor ha hecho lo posible para que el lector responda afirmativamente, los amigos presentes discrepan con vehemencia. El médico que antes había criticado el afán lujoso de José Fernández contesta que este momento en Suiza representa "la única vez que has estado en tu juicio", e imagina lo que se hizo con la riqueza destinada a la modernización nacional. Se gastó en lujo: "Los pasteles trufados de hígado de ganso, el champaña seco, los tintos tibios, las mujeres ojiverdes, las japonerías y la chifladura literaria” (148). Aunque de forma abiertamente irónica, la novela establece una explícita cadena causal entre la producción de riqueza doméstica y su gasto en artículos de lujo extranjeros. Los sueños de una economía nacional más productiva y de cadenas de intercambio transatlántico más balanceados se esfuman.

De sobremesa es una novela en la que el consumo del lujo aventaja a la producción, en una infinita generación deudora. Al final de la novela, José Fernández regresa a Sudamérica sin capital para invertir en el futuro de la nación y sin pareja reproductiva. Su amor por Helena no se realiza porque esta mujer, tanto como su plan de modernización, es una fantasía del diarista. Y aunque él había regresado al hogar para emprender una nueva empresa económica, ésta también fracasa. En cambio, todo lo que conserva son los objetos de lujo que decoran el salón en la escena que abre la novela. Por otro lado, esta fábula sobre el desequilibrio económico y psíquico no se limita a señalar la insolvencia del consumidor latinoamericano de lujo, sino que también utiliza esta figura para destacar los elementos de ensoñación y locura que estructuran los mismos proyectos de modernización desde la periferia, donde hasta el sujeto más “productivo” y viril es asediado por las alzas y bajas de las materias primas, las devaluaciones monetarias y la creciente deuda en el exterior.

EL VALOR DEL ARTISTA

Al reflexionar sobre la importancia de Silva como icono nacional en la Colombia actual, Fernando Vallejo señala que "[n]os enseñaban a los niños en primaria que fue el precursor del modernismo. Sí, y de la deuda latinoamericana también” (92). Pero si bien Silva es el fundador (literario) de la deuda latinoamericana, a lo largo del siglo xx ha acumulado un valor significativo como icono literario en Colombia, hasta el punto de que en 1996, el estado colombiano emitió un nuevo billete de 5.000 pesos para conmemorar la muerte de Silva (Fig. 2). Irónicamente, en un giro que 
habría divertido al mismo Silva, el deudor más sobresaliente de la nación se convierte en la efigie que respalda su moneda. En el anverso del billete, el rostro de Silva aparece a la derecha, en medio de un follaje y fauna exuberantemente tropicales y

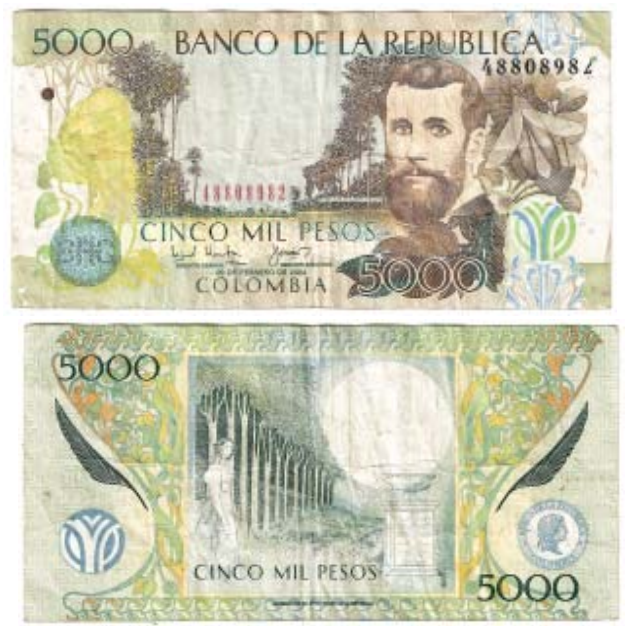

FIgURA 2. Billete de 5.000 pesos colombianos, con la imagen de Silva en el lado anverso, y una representación de su poema "Nocturno" en el reverso.

retratados decididamente en un estilo art noveau. En el reverso, se ve a una mujer de pie, con un largo y ondeante vestido, junto a una arboleda bajo la luz de una enorme luna llena: imagen que ilustra el famoso poema de Silva "Nocturno". A la derecha de la mujer, directamente bajo la luna, aparece una urna en la cual está grabado el poema, que un crítico ha llamado parte del "intangible patrimonio espiritual" de Colombia (Cobo Borda 36). El billete vuelve tangible este patrimonio, pero lo hace a través de la imagen espiritualizada del poeta, al parecer fuera del ámbito de las fluctuaciones diarias en el precio del café, la compra y venta de zapatos importados, y las frecuentes caídas del peso con respecto a la libra esterlina, o como es el caso de hoy, el dólar. Como autor del "Nocturno", Silva puede servir como instrumento de cambio, siempre que calle sus deudas impagables. 
BiBLIOGRAFÍA

Blanco Fombona, Rufino. “José Asunción Silva”. Leyendo a Silva. Juan Gustavo Cobo Borda y Luis Fernando García Núñez, eds. Vol. 1. Bogotá: Instituto Caro y Cuervo, 1994. 67-86.

Brigard Silva, Camilo. “El infortunio comercial de Silva”. Revista de América (May-June 1946): 281-300.

Casal, Julián del. Poesía completa y prosa selecta. Álvaro Salvador, ed. Madrid: Editorial Verbum, 2001.

Cobo Borda, Juan Gustavo, ed. José Asunción Silva. Bogotano universal. Bogotá: Villegas Editores, 1988.

Darío, Rubén. “El rey burgués”. Azul ... El Salmo de la Pluma. Cantos de vida y esperanza y otros poemas [1888]. México: Editorial Porrúa, 1965. 17-20 “Era un aire suave”. SpanishAmerican Modernista Poets: ACritical Anthology [1896]. Gordon Brotherston, comp. Londres: Bristol Classical Press, 1995.

Esteves, Luís. Apuntes para la Historia Económica del Perú. Lima, 1882.

Halperín Donghi, Tulio. The Contemporary History of LatinAmerica. John Chasteen, trad. Durham y Londres: Duke UP, 1993.

Henríquez Ureña, Pedro. Literary Currents in Hispanic America. 1945. Nueva York: Russell \& Russell, 1963.

Huysman, Joris Karl. Against Nature (À rebours) [1884]. Robert Baldick, trad. Londres y Nueva York: Penguin, 2003.

Martí, José. “Nuestra América”. Nuestra América [1891]. Caracas: Biblioteca Ayacucho, 1977. 26-33.

Molloy, Sylvia. "Voice Snatching: De sobremesa, Hysteria, and the Impersonation of Marie Bashkirtseff”. Latin American Literary Review 25/50 (1997): 11-29.

Montero, Oscar. “Escritura y perversión en De sobremesa”. Revista Iberoamericana LXIII/178-179 (1997): 249-61.

Pocock, J.G.A. The Machiavellian Moment. Florentine Political Thought and the Atlantic Republican Tradition. Princeton: Princeton UP, 1975.

Pratt, Mary Louise. Imperial Eyes. Travel Writing and Transculturation. Londres y Nueva York: Routledge, 1992.

Rama, Ángel. Rubén Darío y el modernismo [1970]. Caracas: Alfadil Ediciones, 1985.

Samper, Miguel. "Retrospecto” [1896]. La miseria en Bogotá y otros escritos. Bogotá: Biblioteca Universitaria de Cultura Colombiana, 1969. 135-93.

Santos Molano, Enrique. El corazón del poeta. Los sucesos reveladores de la vida y la verdad inesperada de la muerte de José Asunción Silva [1990]. Bogotá: Presidencia de la República, 1997. 
Sekora, John. Luxury: The Concept in Western Thought, Eden to Smollett. Baltimore: Johns Hopkins UP, 1977.

Silva, José Asunción. Cartas: 1881-1896. Fernando Vallejo, ed. Bogotá: Ediciones Casa Silva, 1996.

“De sobremesa”. Obra completa. Eduardo Camacho Guizado y Gustavo Mejía, eds. Caracas: Biblioteca Ayacucho, 1977. 109-243.

Topik, Steven C., y Allen Wells, eds. Introduction. The Second Conquest of Latin America: Coffee, Henequen, and Oil during the Export Boom, 1850-1930. Austin: U of Texas P, 1998. 1-36.

Vallejo, Fernando. Chapolas negras. Bogotá: Editorial Santillana, 1995.

Watson, Janell. Literature and Material Culture from Balzac to Proust: The Collection and Consumption of Curiosities. Cambridge y Nueva York: Cambridge UP, 1999. 